\title{
The ribbed drapery of the Puerto Princesa Underground River (Palawan, Philippines): morphology and genesis
}

\author{
Paolo Forti ${ }^{1,4^{*}}$, Giovanni Badino ${ }^{1,2}$, José Maria Calaforra ${ }^{1,3}$, and Jo De Waele ${ }^{1,4}$ \\ ${ }^{1}$ La Venta Esplorazioni Geografiche, Treviso, Italy \\ ${ }^{2}$ Department of General Physics, Via Pietro Giuria 1, 10125 Torino, University of Torino, Italy \\ ${ }^{3}$ Department of Biology and Geology, CAES Global Change, University of Almeria, Spain \\ ${ }^{4}$ Department of Biological, Geological and Environmental Sciences, Italian Institute of Speleology, Bologna, Italy
}

\begin{abstract}
During the 2011 speleological expedition to the Puerto Princesa Underground River (Palawan, Philippines) a drapery characterized by several close-to-horizontal ribs has been noticed. Even without sampling and analyzing its internal growth layers, a detailed morphological study allowed to present a possible genetic model. The presented model helps to explain its evolution, which is mainly controlled by variation in water flow as a consequence of the Palawan climate. When validated by further analyses, the same genetic mechanism could define also the evolution of the very common but still unexplained complex flowstones, which exhibit several close-to-horizontal steps, widenings and narrowings along their growth axis.
\end{abstract}

Keywords: Drapery modeling ribs, complex speleothems, genetic model

Received 15 June 2016; Revised 16 December 2016; Accepted 16 December 2016

Citation: $\quad$ Forti P., Badino G., Calaforra J.M. and De Waele J., 2017. The ribbed drapery of the Puerto Princesa Underground River (Palawan, Philippines): morphology and genesis. International Journal of Speleology, 46 (1), 93-97. Tampa, FL (USA) ISSN 0392-6672

https://doi.org/10.5038/1827-806X.46.1.2011

\section{INTRODUCTION}

The morphological characteristics of speleothems are mainly controlled by the type of water flow feeding them (Hill \& Forti, 1997). This characteristic allows for the creation of theoretical models that define the shape of some of the most common speleothems such as stalagmites (Franke, 1965; Curl, 1973; Dreybrodt, 1999; Kaufmann, 2003; Romanov et al., 2008), stalactites (Kaufmann, 2003; Short et al., 2005a, b), and rimstone dams (Wooding, 1991). These models are mainly based on the in-time evolution of supersaturation during the flow of the feeding water over the speleothem.

Detailed geochemical (stable isotope) studies and petrography on speleothems can reveal the processes that caused the feeding water to precipitate carbonate (mainly calcite and aragonite), and thus the evolution of waters in underground environments due to a variety of processes active in these environments (i.e., differential $\mathrm{CO}_{2}$ and/or $\mathrm{H}_{2} \mathrm{O}$ loss from a water film, differential aerosol deposition, deposition in subaqueous environments) (Caddeo et al., 2015). Recent studies focused on the effect of the steady flow hydrodynamics in developing "crenulations" (ripplelike structures characterized by a wavelength close to $1 \mathrm{~cm}$ ) over stalactites, stalagmites and flowstones
(Camporeale \& Ridolfi, 2012; Vesipa et al., 2015). In this case the variation of the supersaturation was induced by changes in the thickness of the water film and/or the development of micro-bubbles of gas within the water, inducing enhanced diffusion of $\mathrm{CO}_{2}$ to the cave atmosphere. All these models are based on the assumption of stationary homogeneous flow conditions. In reality, most speleothems display complex morphological patterns that develop in unsteady or heterogeneous flow conditions. Those conditions still require explanation from a genetic point of view.

This is the case of an astonishing "ribbed" drapery observed in the Puerto Princesa Underground River (PPUR) (Palawan, Philippines) during the 2011 La Venta expedition (Piccini \& Iandelli, 2011; Coombes et al., 2015) (Fig. 1A). Until present, a drapery of this kind was never described in other caves in the world and this exploration offered the unique possibility to try and understand the special conditions that controlled the evolution of this speleothem. Because the PPUR is a protected area, and the speleothem is unique, sampling was not carried out. Nevertheless, modeling results from previous authors and basic scientific principles make it possible to propose a genetic mechanism for the formation of this ribbed drapery. 


\section{MORPHOLOGY OF THE PPUR DRAPERY}

The ribbed drapery, located approximately $2 \mathrm{~km}$ from the cave entrance (Fig. 1A), is developed along the God's Highway, a strait $600 \mathrm{~m}$ long by $10-20 \mathrm{~m}$ wide by $15 \mathrm{~m}$ high SW-NE oriented passage through which flows the PPUR river. This drapery, over 10 $\mathrm{m}$ long, is characterized by the presence, along its lateral sides, of several close-to-horizontal symmetric ribs (Fig. 1B). The distance between the ribs ranges from a few decimeters to over $1 \mathrm{~m}$, while their size is from a few to $20-30 \mathrm{~cm}$ wide. The increase in rib size corresponds to a larger deviation from the horizontality: in fact the largest ones are clearly bent upward with possible interference with the upper ribs, which may eventually be incorporated. Finally, at least in the area close to the contact with the cave wall (1 in Fig. 1B) it is evident that, at the beginning, the process was characterized by a higher number of smaller ribs, which progressively coalesced forming some larger ribs. The vertical section of the drapery is characterized by close-to-horizontal zones of sudden enlargement, followed by a downward, fast progressive reduction until its "normal" thickness is re-established. The enlargements are always symmetrical, being of the same size and at the same level on both sides of the drapery.

\section{CAVE CLIMATE AND WATER REGIME}

Palawan is located in the Intertropical Convergence Zone and therefore its average temperature is relatively high $\left(\sim 27^{\circ} \mathrm{C}\right)$ with daily, monthly and yearly excursion rarely exceeding $\pm 5^{\circ} \mathrm{C}$. The annual average relative humidity is high and almost constant staying around $80-85 \%$.

The climate is "tropical wet and dry" (Aw in the Köppen climate classification): the wettest month is September while the driest month is February. The average rainfall is relatively high (close to $2,000 \mathrm{~mm} / \mathrm{yr}$ ), and $95 \%$ of it falls during the wet (monsoon) period (from May to November) and it is concentrated in few, short but heavy rainstorms.

Consequently the PPUR climate is extremely stable (Badino, 2010, 2013), controlled by the general island climate and by the ocean, which, during the dry season, floods every 12 hours a large part of the cave with more than $100,000 \mathrm{~m}^{3}$ of sea water (Forti, 2014). The flow regime within the PPUR dramatically changes from dry to wet period (the outflow discharge rises from less than $200 \mathrm{l} / \mathrm{s}$ to much more than $10 \mathrm{~m}^{3} / \mathrm{s}$ in only a few couples of hours): thus most of the hosted speleothems are active only during the floods but dry all the rest of the time.

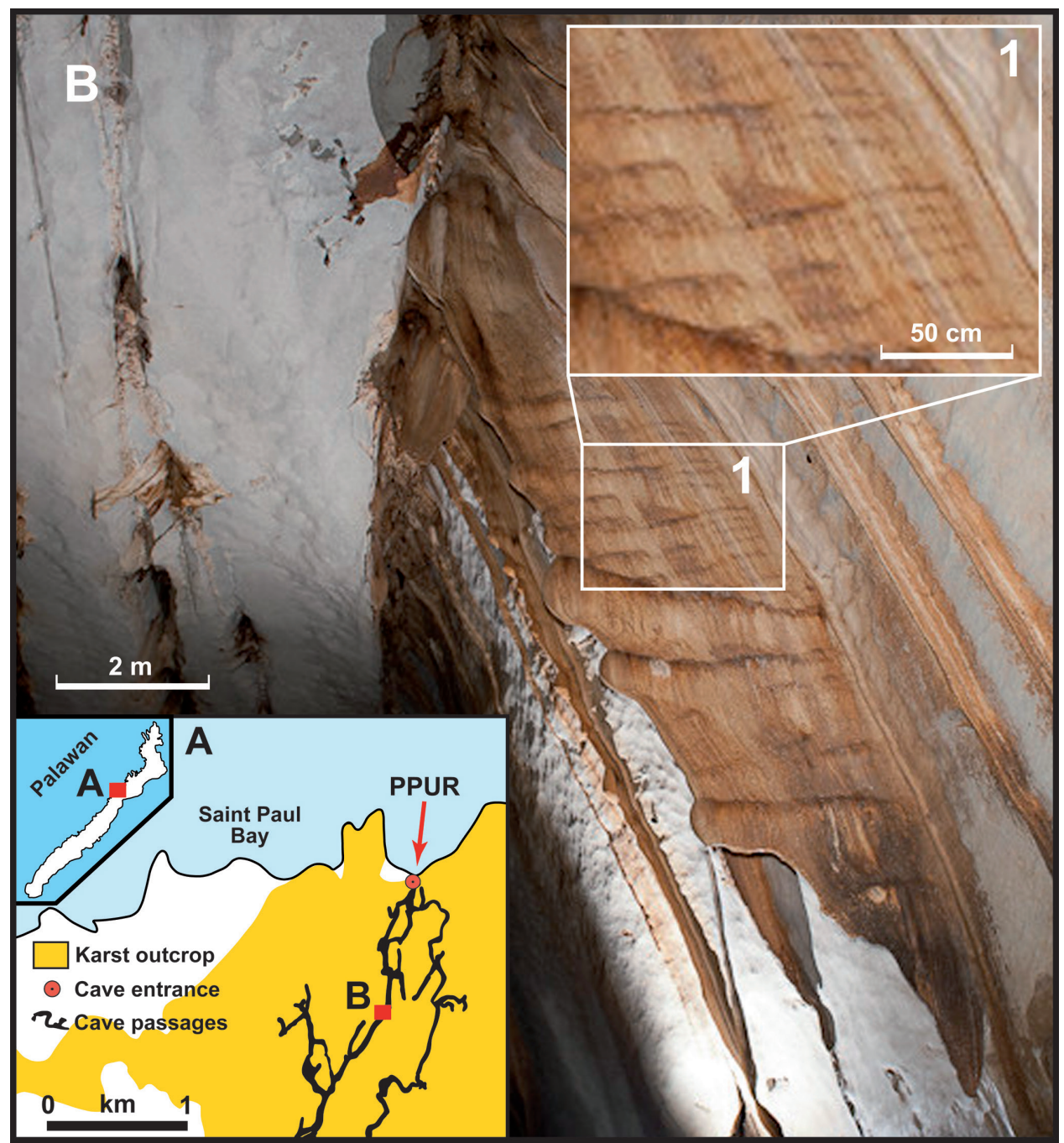

Fig. 1. A) Location map of the PPUR; B) The ribbed drapery (photo by Natalino Russo, La Venta Esplorazioni Geografiche); 1) enlargement to highlight the mechanism of progressive coalescence of the small ribs starting with the closest ones giving rise to a few larger ribs. 
The very high external relative humidity together with the extremely narrow temperature fluctuation and the presence within the cave of an enormous free water surface, greatly inhibit evaporation processes that are subdued in the presence of relatively high air currents (up to $1.5 \mathrm{~m} / \mathrm{s}$ displacing over $100 \mathrm{~m}^{3} / \mathrm{s}$, Badino, unpublished data). However, in some places of the cave system it is sometimes possible to see active condensation processes with the development of large clouds, the genesis of which is induced by cold air currents coming from the upper cave levels. This phenomenon has been observed when rainstorms that occur in the hot season cause a local lowering of cave temperatures. This occurs when cooler percolation water originating from the top of the mountain rapidly reaches the main cave passages. This phenomenon may also explain the fact that in the thermostable area of the cave the average temperature is almost $2{ }^{\circ} \mathrm{C}$ lower than the external one.

\section{GENESIS OF THE RIBBED DRAPERY}

Normally the genesis, and most of the evolution, of a drapery is induced by water flowing exclusively along its external (lower-outer) edge, while the possible laminar flow on both sides of the speleothem can only enlarge its thickness without changing its shape and/or structure. The morphology of the PPUR drapery suggests that this conditions of enhanced deposition exclusively occur in the widened zones, where enlargement takes place. It is also clear that many of these initially favorable deposition zones enlarged themselves progressively merging with neighboring ribs giving rise to the evolution of the larger ribs (1 in Fig. 1B).

It is evident that the flow along the lower/outer edge of the drapery, which allows deposition along its, cannot justify the evolution of the ribs. These enlargements have to be caused by water flowing along the lateral sides of the drapery. In the PPUR cave system, the lateral sides of the draperies are totally dry most of the time, subjected to active flow only during rainstorms characterizing the wet season of Palawan. During these rare and relatively short (from few hours to a couple of days) events the water flow may also become very important and fast. We believe that ribs can grow only during such rainy periods, when wet conditions on the lateral sides of the drapery are easily achieved.

Evaporation processes are not considered important factors for inducing the sudden increase in supersaturation because, when the water flow is present, evaporation is very low or non-existant. There are several reasons for this: first because active dripping water occurs mostly during rainstorms, when, even in the hot seasons, the percolating waters are cooler than the cavern environment, which in turn is already saturated or even oversaturated with respect to $\mathrm{H}_{2} \mathrm{O}_{(\mathrm{g})}$ (Badino, 2013). It would also be extremely complex to justify the perfectly symmetric development of the ribs on both drapery sides by evaporation, since this would mean that air currents would have to flow preferentially where the ribs are growing. Furthermore, the Palawan climate, characterized by stable temperatures and low diurnal and annual thermal excursion, along with the oceanic effect of a large entrance and underground river connection to the ocean, and the influence of tides on cave atmosphere, do not allow symmetrically distributed air flow during rainstorms.

Discarding evaporation as a possible cause, the water flow over the drapery sides is the only possible factor able to induce the sudden stationary supersaturation at the position where the ribs develop. To understand the development of the ribs, it is fundamental to define how the first symmetric discontinuities, which later induced the evolution of the ribs, were formed.

The fact that all the "embryonic" ribs are closeto-horizontal and always at the same level on both sides strongly support the hypothesis that a single simultaneous process is responsible for their genesis. The increase in flow rate and velocity (with possible transition from laminar steady flow to subcritical or critical flow) (Chanson, 2009, 2012) affects the shape and the thickness of the water layer with consequent local narrowings or enlargements. This may cause the splitting-up of the water film due to insufficient surface tension (Eggers, 1997). Such events are greatly enhanced by the irregularities of the rock over which the drapery starts to develop

All these phenomena, locally lowering the internal pressure of the water film, not only cause an enhanced $\mathrm{CO}_{2}$ diffusion into the cave atmosphere, but also induce the development of micro-bubbles of $\mathrm{CO}_{2}$ within the solution (Brennen, 1995). The presence of these bubbles further increases the supersaturation, such that they will not be so easily reabsorbed when the original condition of laminar flow is restored.

In this manner any further even minimal decreases of the fluid's internal pressure enhances bubble development, thus inducing a relatively high increase in supersaturation downstream of where bubbles are formed. Finally, these instabilities in the water regime are responsible for a local decrease of the flow rate. These processes increase the deposition of $\mathrm{CaCO}_{3}$ due to enhanced supersaturation and an increase in time of water-drapery surface contact over a short distance. This also causes a decrease of the steepness of the drapery edge and/or an increase in roughness. Being induced by local factors, these discontinuities develop in places that may result at regular intervals.

When at the end of a pulse the water flow ends, evaporation will become active for just a short time lapse: as a result of capillary uplift, this process will be efficient mainly on top of the small protrusions. In this manner the protrusions, generated by the critical flow during the rainstorms, undergo a slight lateral enlargement exactly at the same level on both sides of the drapery. The subsequent flows and dry periods are obviously forced to induce the same effects exactly on the same protrusions. The final result will be the development of embryonic close-tohorizontal ribs (Fig. 2A1). In conclusion, the variation of the water flow over the drapery edge is the only possible parameter responsible for the development of the embryonic ribs. 
It is evident that the water flow along the lower/outer edge cannot induce the deposition of calcium carbonate along the lateral sides of the drapery, therefore other processes must control the progressive enlargement of the ribs. The Palawan climate influences the water regime over the lateral sides even more than on the drapery edge: consequently the flow regimen variations and induced supersaturation discussed earlier are also valid here. The only difference is that close-tohorizontal embryonic ribs already exist on the lateral sides and therefore flow perturbations are forced to occur exactly on these protrusions: so the consequent enhanced deposition will progressively enlarge them.

The rib enlargement will be a rapid process because just below the point of abrupt decrease of steepness, the convex shape of the rib will activate the enhanced $\mathrm{CO}_{2}$ diffusion phenomenon (2 in Fig. 2A): practically this is the same well-known process allowing the selective deposition just on top of the rimstone dams (Wooding, 1991; Hill \& Forti, 1997). The protrusions, i.e., the ribs, are the favored place for capillary uplift and evaporation (Badino et al., 2011), because they are slightly enlarged by selective deposition. This process occurs when the water flow over the lateral sides ends and the water layer completely dries up.

The growth of all the embryonic ribs continues until their dimensions interfere with the next rib causing a progressive coalescence of some of them into a larger one. This explains the existence of ribs of very different size but of the same age (1 in Fig. 1B).

The feature yet to be explained is the progressive upward deflection of the largest ribs towards the drapery edge (Fig. 1B). As progressive enlargement occurs along all of the ribs, it also occurs along the drapery edge. As a result the edge thickens and the shape progressively increases. But the portion of the rib over its lower edge will continue growing not only during the short period of water flow along the drapery sides, but also during the longer ones in which drip flow is active just over the lower (outer) edge. As a consequence the deposition on the lower edge will necessarily be slightly greater than that on both drapery sides, inducing a progressive upward growth of the rib towards the edge (Fig. 2B).

In particular during high water flows, the greater supersaturation occurs just above the point where turbulent flow begins and will rapidly decrease downstream due to the $\mathrm{CaCO}_{3}$ deposition, which will completely stop far before the end of the convex shape of the rib (1 in Fig. 2B). At the end of the water pulse, when for a short span of time the dominant processes are capillary movement and evaporation, the deposition will migrate toward the most prominent sites, specifically to the top of the small domes protruding from the drapery edge (2 in Fig. 2B), which will slowly expand.

Due to the presence of larger close-tohorizontal (or at least less sloping) surfaces, the efficiency of the just outlined process is proportional to the size of the ribs and therefore the upward deflection is directly controlled by the rib size.

In conclusion, the fundamental factor ruling the development of the ribbed drapery of the PPUR is the unique climate of Palawan Island, that is characterized by long dry periods interrupted by heavy rainstorms. In fact, it is the great variability of the feeding water which allows not only the genesis of the close-tohorizontal symmetric embryonic ribs induced by the perturbation of the flow along the external edge of the drapery, but also their progressive evolution due to the water flow along both lateral sides. The alternation of dry and wet periods also justifies the possible coalescence of two or more ribs to form a larger one and it is also responsible for the slight upward deflection, more evident in the larger ribs.

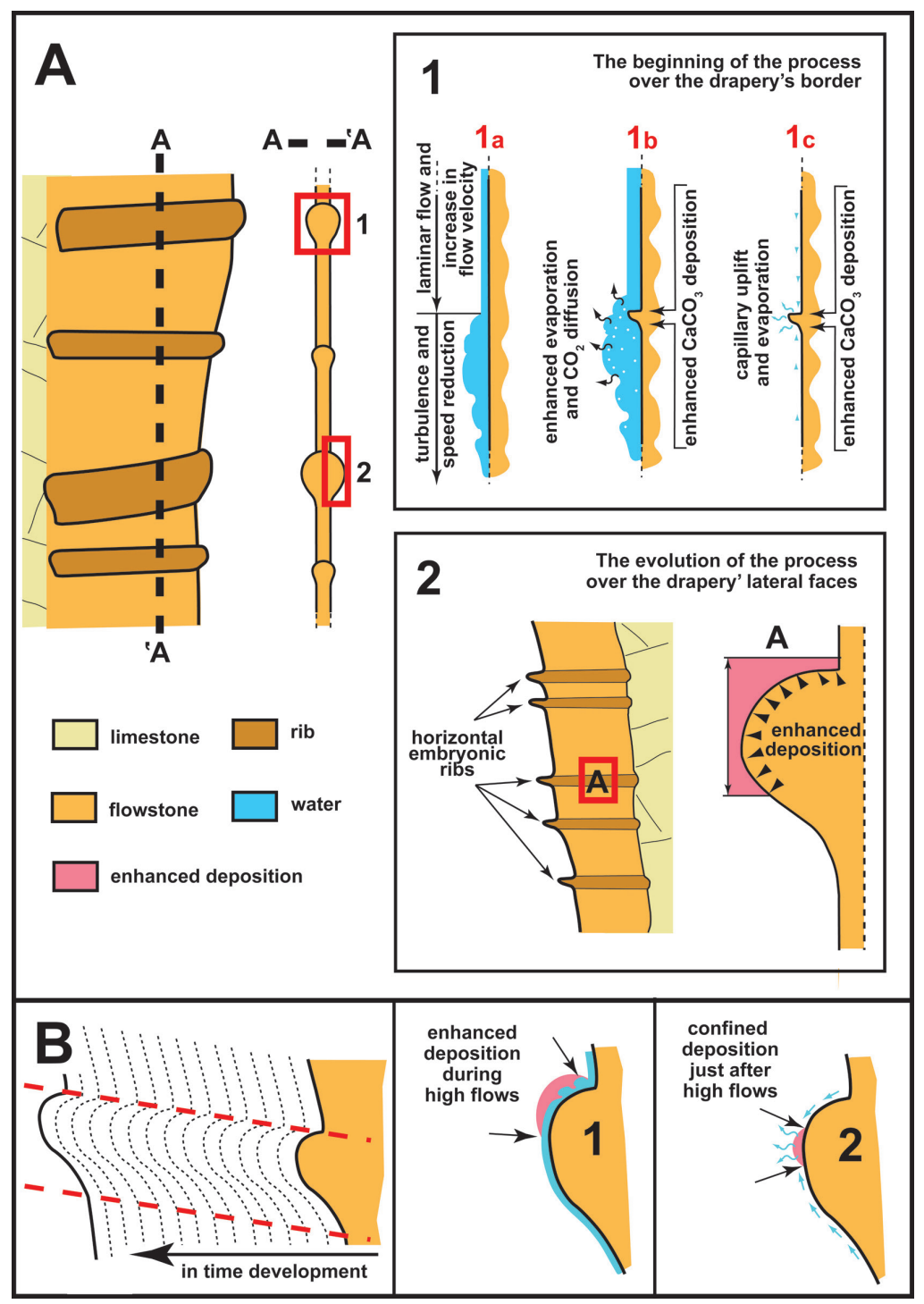

Fig. 2. A) Sketch of the drapery showing the shape of the ribs. 1: the beginning of the process on the external edge of the drapery: during the rainstorm the fast flow induces turbulences (1a), which in turn locally enhance the deposition rate (1b). This process is still active for a short period after the complete stop of the flow (1c) due to capillary uplift and evaporation, which causes also a slight lateral enlargement on both sides of the drapery; 2 : the evolution of the embryonic ribs on the lateral sides is driven by the same processes active over the edge;

B) Development of a rib along a longitudinal section: the slightly higher deposition occurring over the external edge will cause a progressive upward deflection of the rib axis: 1: during water pulses turbulence will induce the highest supersaturation in the upper convex part of the rib; 2: at the end of the water pulse capillary uplift and evaporation concentrate in the rib's most protruding part, which progressively increases its protrusion from the rib edge. 
The processes ruling the genesis and the development of this unique drapery are of the "positive feedback" type. In fact, when in a given point the condition of preferential deposition is attained, this process progressively increases the further deposition exactly in the same point. This happens because the presence of a discontinuity enhances both changes in the flow regimen during water pulses and evaporation at the beginning of the dry periods.

\section{CONCLUSIONS}

The morphological analysis of the Puerto Princesa Underground River (PPUR) ribbed drapery suggest that its evolution is totally controlled by the flow regime over both its lateral sides during the short but strong rainstorms, while the consequent transition from subcritical to critical flow velocity and/or by the variation in the water layer thickness are the parameters ruling the development of the drapery ribs. The UNESCO World Heritage Site status that is afforded to PPUR does not allow destructive analyses of any of its hosted speleothems so it is not possible to experimentally confirm the proposed genetic mechanism.

Stepped flowstones and speleothems similar to the PPUR drapery ribs are present in other caves of the world so it is possible in the future to be able to conduct the required analyses to validate our model.

Once confirmed, the genetic-evolutionary mechanisms ruling the formation of this unique drapery may be useful to better define those controlling the development of other speleothems, which were never analyzed from the genetic point of view until present, despite their widespread occurrence in caves all over the World: the "stepped" flowstones.

\section{ACKNOWLEDGEMENTS}

We thank P. Kambesis for carefully reviewing our manuscript and providing suggestions that helped improve the paper.

\section{REFERENCES}

Badino G., 2010 - Underground meteorology. What's the weather underground? Acta Carsologica, 39 (3): 427-448. https://doi.org/10.3986/ac.v39i3.74

Badino G., 2013 - Where are the hottest caves in the world? Kur 20: 43

Badino G., Calaforra J.M., Forti P., Garofalo P. \& Sanna L., 2011 - The present day genesis and evolution of cave minerals inside the Ojo de la Reina cave (Naica Mine, Mexico). International Journal of Speleology, 40 (2): 125-131.

https://doi.org/10.5038/1827-806X.40.2.5

Brennen C.E., 1995 - Cavitation and bubble dynamics. Oxford University Press, 268 p.

Caddeo G.A., Railsback L.B., De Waele J. \& Frau F., 2015 - Stable isotope data as constraints on models for the origin of coralloid and massive speleothems: the interplay of substrate, water supply, degassing, and evaporation. Sedimentary Geology, 318: 130-141.

https://doi.org/10.1016/j.sedgeo.2014.12.008
Camporeale C. \& Ridolfi L., 2012 - Hydrodynamic-driven stability analysis of morphological patterns on stalactites and implications for cave paleoflow reconstruction. Physical Review Letters, 108: 238501.

https://doi.org/10.1103/PhysRevLett.108.238501

Chanson H., 2009 - Current knowledge in hydraulic jumps and related phenomena. a survey of experimental results. European Journal of Mechanics B/Fluids, 28 (2): 191-210.

https://doi.org/10.1016/j.euromechflu.2008.06.004

Chanson H., 2012 - Momentum considerations in hydraulic jumps and bores. Journal of Irrigation and Drainage Engineering, 138 (4): 382-385.

https://doi.org/10.1061/(ASCE)IR.19434774.0000409

Coombes M.A., La Marca E.C., Naylor L.A., Piccini L., De Waele J. \& Sauro F., 2015 - The influence of light attenuation on the biogeomorphology of a marine karst cave: a case study of Puerto Princesa Underground River, Palawan, the Philippines. Geomorphology, 229: 125-133.

https://doi.org/10.1016/j.geomorph.2014.10.007

Curl R.L., 1973 - Minimum diameter of stalagmites. National Speleological Society Bulletin, 35 (1): 1-9.

Dreybrodt W., 1999 - Chemical kinetics, speleothem growth and climate. Boreas, 28 (3): 347-356. https://doi.org/10.1080/030094899422073

Eggers J., 1997 - Nonlinear dynamics and breakup of free-surface flows. Reviews of Modern Physics, 69 (3): 865-929.

https://doi.org/10.1103/RevModPhys.69.865

Forti P. (ed.), 2014 - Puerto Princesa Underground River (Palawan, Philippines): Bathimetric, hydrochemical, hydrodynamical and thermometric data. Map, Kur 21.

Franke H.W., 1965 - The theory behind stalagmite shapes. Studies in Speleology, 1 (2-3): 89-95.

Hill C.A. \& Forti P., 1997 - Cave minerals of the world. National Speleological Society, Huntsville, USA, 463 p.

Kaufmann G., 2003 - Stalagmite growth and palaeoclimate: the numerical prespective. Earth and Planetary Science Letters, 214: 251-266. https://doi.org/10.1016/S0012-821X(03)00369-8

Piccini L. \& Iandelli N., 2011 - Tectonic uplift, sea level changes and Plio-Pleistocene evolution of a coastal karst system: the Mount Saint Paul (Palawan, Philippines). Earth Surface Processes and Landforms, 36 (5): 594-609. https://doi.org/10.1002/esp.2078

Romanov D., Kaufmann G. \& Dreybrodt W., 2008 - Modeling stalagmite growth by first principles of chemistry and physics of calcite precipitation. Geochimica et Cosmochimica Acta, 72 (2): 423-437. https://doi.org/10.1016/j.gca.2007.09.038

Short M.B., Baygents J.C. \& Goldstein R., 2005a Stalactite growth as a free-boundary problem. Physics of Fluids, 17: 083101.

https://doi.org/10.1063/1.2006027

Short M.B., Baygents J.C., Warren Beck J., Stone S. A., Toomey III R.S. \& Goldstein R.E., 2005b - Stalactite growth as a free-boundary problem: a geometric law and its platonic ideal. Physical Review Letters, 94: 018501. https://doi.org/10.1103/PhysRevLett.94.018501

Vesipa R., Camporeale C. \& Ridolfi L., 2015 - Thin-filminduced morphological instabilities over calcite surfaces. Proceedings Royal Publishing Society A, 471 (2176): 20150031. https://doi.org/10.1098/rspa.2015.0031

Wooding R., 1991 - Growth of natural dams by deposition from steady supersaturated shallow flow. Journal of Geophysical Research Solid Earth, 96 (B1): 667-682. https://doi.org/10.1029/90JB01944 